\title{
ANALISIS KANDUNGAN RADIONUKLIDA PADA GAS BUANG CEROBONG REAKTOR SERBAGUNA G.A. SIWABESSY
}

\author{
Sriyono \\ Pusat Teknologi dan Keselamatan Reaktor Nuklir - BATAN \\ Email: sriyono@batan.go.id
}

\begin{abstract}
ABSTRAK
ANALISIS KANDUNGAN RADIONUKLIDA PADA GAS BUANG CEROBONG REAKTOR SERBAGUNA G.A. SIWABESSY. RSG-GAS adalah reaktor penelitian yang telah berumur lebih dari 30 tahun. Gas buang yang berasal dari dalam gedung dibuang ke lingkungan melalui cerobong dan selalu dipantau kandungan radionuklidanya. Selama RSG-GAS beroperasi dimungkinkan ada sejumlah zat radioaktif terlepas ke atmosfer. Radionuklida yang terlepas ini dapat berasal dari aktivasi unsur-unsur yang terbawa dalam pendingin dan juga kemungkinan lepasan dari gas produk fisi dari teras reaktor. Tujuan pemantauan terhadap lepasan radionuklida agar tidak membahayakan pekerja dan lingkungan sekitar reaktor. Analisis ini dilakukan berdasarkan Laporan Operasi Reaktor (LOR) 10 tahun terakhir. Batas paparan maksimum dari gas buang adalah $1 \times 10^{15} \mathrm{~Bq} / \mathrm{m}^{3}$. Ada 2 kondisi operasi yang disampling, yaitu kondisi operasi $0 \mathrm{MW}$ dan kondisi operasi $15 \mathrm{MW}$. Pada saat reaktor shutdown nilai paparan radionuklida dari cerobong jauh lebih kecil dibandingkan pada saat operasi. Perbedaan itu diperkirakan rata-rata sebesar $5 \times 10^{3} \mathrm{~Bq} / \mathrm{m}^{3}$. Pada saat operasi $15 \mathrm{MW}$, kenaikan paparan diperkirakan berasal dari perubahan sistem reaktor, dari sistem yang statis menjadi sistem dinamis. Hasil pengukuran paparan radiasi yang berasal dari gas mulia pada cerobong RSG GAS masih dibawah ambang batas yang ditetapkan pada LAK (Laporan Analisis Keselamatan) yaitu 1 x $10^{15} \mathrm{~Bq} /$ $\mathrm{m}^{3}$.
\end{abstract}

Kata kunci: radionuklida, gas buang, cerobong, RSG GAS

\section{ABSTRACT}

THE ANALYSIS OF RADIONUCLIDES CONTENT IN THE STACK OF MULTIPURPOSES REACTOR G.A. SIWABESSY. RSG-GAS is a 30 years old research reactor. The exhaust gases from inside reactor building are discharged into the environment through the stack. The monitoring of radionuclide content and radiation exposure released into the environment from the stack is done during the shutdown and operation. Due to the reactor operation, some radioactive substances may be released into the atmosphere. This detachable radionuclide can be derived from the material activation carried in the coolant and also the possibility of fission product gas release from the reactor core. The purpose of radionuclide release monitoring is to protect the workers and the environment surrounding the reactor. The methodology used in this research is the analysis of radionuclide content based on RSG-GAS Operation Report for the last 10 years. The maximum radiation exposure limit of the flue gas is $1 \times 10^{15} \mathrm{~Bq} / \mathrm{m}^{3}$. There are two operating conditions to be sampled, which are at $0 \mathrm{MW}$ and $15 \mathrm{MW}$. During $0 \mathrm{MW}$, the radiation exposure value from the chimney is much smaller than at $15 \mathrm{MW}$. The difference is estimated to $5 \times 10^{3} \mathrm{~Bq} / \mathrm{m}^{3}$ of average. At $15 \mathrm{MW}$, increasing radiation exposure is caused by reactor condition changes from a static condition to a dynamic condition. The measurement of noble gases in the chimney is still below the limits of $1 \times 10^{15} \mathrm{~Bq} / \mathrm{m}^{3}$ as specified in the Safety Analysis Report.

Keywords: radio nuclides, exhaust gas, stack, RSG GAS 


\section{PENDAHULUAN}

Reaktor Serba Guna Siwabessy (RSGGAS) dibangun sejak tahun 1983. Pencapaian kritis pertama dicapai pada bulan Juli 1987 dan kemudian diresmikan oleh Presiden RI, Bapak Soeharto, pada tanggal 20 Agustus 1987. Operasi dengan daya penuh 30 MW dicapai pertama kali pada bulan Maret 1992. RSG-GAS mempunyai daya termal maksimum $30 \mathrm{MW}$ dan mempunyai fluks neutron rata-rata $10^{14} \mathrm{n} /$ $\mathrm{cm}^{2}$.detik yang berasal dari reaksi fisi. RSGGAS adalah reaktor dengan jenis kolam berbahan bakar $\mathrm{U}_{3} \mathrm{O}_{8} \mathrm{Al} / \mathrm{U}_{3} \mathrm{Si}_{2} \mathrm{Al}$ dengan pengayaan ${ }^{235} \mathrm{U}$ sebesar $19,75 \%{ }^{[1,2]}$.

RSG-GAS didesain mampu beroperasi sampai dengan daya 30 MW. Pada beberapa tahun terakhir untuk tujuan optimalisasi secara rutin dioperasikan hanya sampai daya $15 \mathrm{MW}$. Reaktor ini dioperasikan untuk tujuan penelitian, produksi isotop, iradiasi topaz, uji bahan bakar, dan lain-lain ${ }^{[3]}$. Pada saat RSGGAS beroperasi ada sejumlah zat radioaktif yang mungkin terlepas ke atmosfer. Radionuklida yang terlepas ini dapat berasal dari aktivasi unsur-unsur yang terbawa dalam pendingin dan juga kemungkinan lepasan dari gas produk fisi. Untuk memantau lepasan radionuklida yang berasal dari kolam reaktor maka diperlukan beberapa komponen filter sebelum gas/udara dari dalam reaktor dibuang ke lingkungan melalui cerobong ${ }^{[4]}$.

Untuk menjamin agar selama kegiatan pengoperasian RSG-GAS tidak membawa dampak bagi personil/manusia, pekerja radiasi maupun lingkungan, maka diperlukan adanya sistem pengaman dan kendali yang cukup handa $\mathrm{l}^{[5]}$. Program pemantauan daerah kerja merupakan upaya untuk mewujudkan keselamatan dengan melakukan kegiatan pemantauan laju dosis radiasi, tingkat kontaminasi udara dan permukaan daerah kerja dan konsentrasi udara buang dari cerobong ke lingkungan ${ }^{[6]}$. Beberapa radionuklida harus dicermati karena apabila terlepas ke lingkungan akan membahayakan pekerja ataupun masyarakat umum. Efluen (gas buang) yang mengandung unsur radioaktif dari reaktor riset memberikan kontribusi terhadap paparan radiasi ke lingkungan dan masyarakat di sekitar reaktor tersebut. Oleh karena itu pemantauan dan pengukuran kandungan emisi udara radioaktif dari cerobong reaktor ke lingkungan harus diteliti dan dicermati dengan baik terhadap efluen cair maupun gas. Alat pemantau harus dapat mendeteksi secara dini kemungkinan meningkatnya aktivitas radioaktivitas yang terlepas. Data lepasan udara radioaktif ke lingkungan perlu dilaporkan ke instansi terkait secara rutin sedikitnya sekali setahun, khususnya jenis dan aktivitas radionuklidanya. Radionuklida dari efluen udara pembangkit nuklir sesuai dengan dokumen AMDAL (Analisis Mengenai Dampak Lingkungan), dikelompokkan menjadi 5 bagian yaitu gas mulia radioaktif, partikulat radioaktif, radio-iodin, tritium (H-3) dan Karbon-14 (C-14).

Makalah ini membahas hasil analisis kandungan radionuklida pada cerobong RSG GAS. Metodologi yang digunakan adalah menganalisis kandungan radionuklida cerobong berdasarkan Laporan Operasi (LOR) RSG-GAS selama 10 tahun terakhir. Pengambilan sampel cerobong dilakukan pada setiap siklus operasi pada daya $0 \mathrm{MW}$ dan $15 \mathrm{MW}$. Pengambilan sampel gas buang dengan cara menjebak ke dalam filter atau carbon trap ${ }^{[7]}$. Pada desain RSG-GAS, sebelum keluar dari cerobong telah dilengkapi dengan saluran udara tempat pemantauan udara buangan dan pengambilan sampel. Kegiatan pemantauan lepasan udara buang dari cerobong di RSGGAS dilakukan dengan cara mengambil sampel buangan efluen gas sebelum dilepaskan ke atmosfir dengan pompa hisap ${ }^{[8]}$. Udara yang di cuplik dialirkan kedalam sebuah sistem pengukur menggunakan fiber filter (filter serat kaca) dan charcoal (arang aktif), kemudian udara dialirkan kembali ke cerobong ${ }^{[9]}$. Filter serat kaca menangkap partikel-partikel aktif yang ada pada udara hisap sedangkan arang aktif menangkap gas Iodium ${ }^{[10]}$. Dengan terpantaunya radionuklida setiap saat, maka dapat dideteksi kandungan radionuklida agar tidak melebihi nilai ambang batas ${ }^{[11]}$. 


\section{METODOLOGI}

Analisis gas buang RSG-GAS dilakukan berdasarkan Laporan Operasi Reaktor dan hasil-hasil penelitian yang telah dipublikasi. Berdasarkan rancangan gedung Reaktor Serba Guna GA. Siwabessy (RSG-GAS) gas buang yang dihasilkan dalam reaktor sebelum keluar ke lingkungan dipantau terlebih dahulu di cerobong (sistem KLK06 CR004). Di sistem ini telah dilengkapi dengan saluran udara tempat pemantauan udara buangan dan pengambilan sampel ${ }^{[9]}$. Kegiatan pemantauan lepasan udara buang dari cerobong di RSG-GAS dilakukan dengan cara mengambil sampel buangan efluen gas sebelum dilepaskan ke atmosfir dengan pompa hisap. Udara yang di cuplik dialirkan ke dalam sebuah sistem pengukur menggunakan fiber filter (filter serat kaca) dan charcoal (arang aktif), kemudian udara dialirkan kembali ke cerobong. Filter serat kaca menangkap partikel-partikel aktif yang ada pada udara hisap sedangkan arang aktif menangkap gas Iodium dan radionuklida lain ${ }^{[10]}$.

Cuplikan/sampel yang telah diambil dari sistem KLK06 CR004 selanjutnya diukur radioaktivitasnya menggunakan spectrometer $\gamma$. Pengukuran aktivitas dengan spektrometer $\gamma$ dilakukan menggunakan detektor high purity germanium (HPGe) yang memiliki efisiensi relatif $10 \%$. Arang aktif cuplikan dimasukkan ke dalam wadah merinelli ditempatkan di atas permukaan planset detektor HPGe. Secara lengkap prosedur pengambilan sampel adalah sebagai berikut ${ }^{[11]}$ :

1. Mempersiapkan alat hisap, dan fiber filter dan charcoal seperti ditunjukkan pada Gambar 1.

2. Dilakukan pengisapan udara cerobong selama 600 menit dengan masingmasing filter.

3. Setelah selesai, filter diambil dan ditempatkan dalam planset kemudian dicacah menggunakan MCA (Multichannel Analyzer)

4. Peralatan MCA sebelum digunakan harus dikalibarasi terlebih dahulu.

5. Hasil pencacahan kemudian dianalisis kandungan radionuklida yang tertangkap dalam sampel filter.

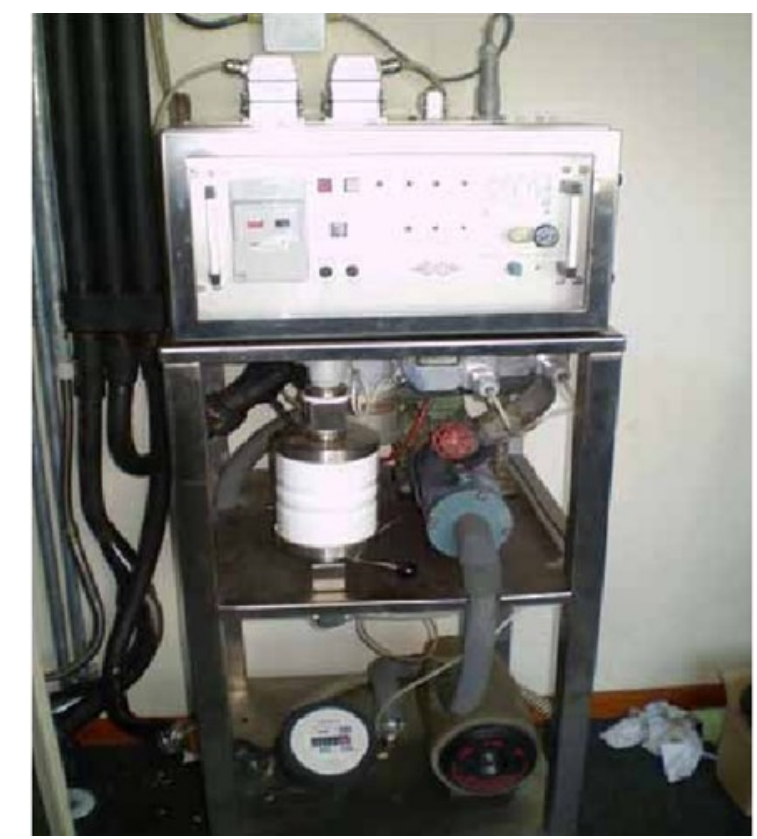

Gambar 1. Peralatan pompa hisap pengambilan sampel cerobong RSG GAS ${ }^{[11]}$ 


\section{HASIL DAN PEMBAHASAN}

Analisis telah dilakukan terhadap kandungan gas buang RSG-GAS berdasarkan Laporan Operasi Reaktor periode 2005-2015. Hasil laporan pengukuran gas mulia (noble gas) pada cerobong RSG GAS ditampilkan secara acak per lima tahunan ditunjukkan pada Tabel 1 sampai dengan Tabel 4. Pada tabel-tabel terse- but ditampilkan pengukuran kandungan gas mulia pada cerobong RSG-GAS pada daya 0 MW dan 15 MW. Pengukuran pada daya 0 MW adalah pada saat reaktor tidak beroperasi, sedangkan pengukuran pada daya 15 MW dilakukan pada saat RSG-GAS beroperasi pada daya maksimum siklus operasi tersebut.

Tabel 1. Hasil uji gas mulia (noble gas) pada cerobong RSG-GAS pada saat operasi Teras 50 (Tahun 2005) ${ }^{[5]}$

\begin{tabular}{|c|c|c|c|c|c|c|}
\hline \multirow[t]{3}{*}{ No } & \multirow[t]{3}{*}{ Lokasi Pengukuran } & \multirow{3}{*}{$\begin{array}{c}\text { Spesifikasi } \\
\text { Teknis } \\
\left(\mathrm{Ci} / \mathrm{m}^{3}\right)\end{array}$} & \multicolumn{4}{|c|}{ Hasil pengukuran $\left(\mathrm{Ci} / \mathrm{m}^{3}\right)$} \\
\hline & & & \multicolumn{2}{|c|}{ 0 MW } & \multicolumn{2}{|c|}{$15 \mathrm{MW}$} \\
\hline & & & Rerata & Maks & Rerata & Maks \\
\hline 1. & $\begin{array}{l}\text { Stack } \\
\text { (KLK06 CR002) }\end{array}$ & $\leq 10^{-4}$ & $1,2 \times 10^{-4}$ & $1,5 \times 10^{-7}$ & $2,5 \times 10^{-7}$ & $3 \times 10^{-7}$ \\
\hline 2. & $\begin{array}{l}\text { Stack } \\
\text { (KLK06 CR001) }\end{array}$ & $\leq 10^{-4}$ & $1,0 \times 10^{-7}$ & $1,2 \times 10^{-7}$ & $2,2 \times 10^{-7}$ & $3 \times 10^{-7}$ \\
\hline
\end{tabular}

Tabel 2. Hasil uji gas mulia (noble gas) pada cerobong RSG GAS pada saat operasi Teras 66 (Tahun 2009) $^{[5]}$

\begin{tabular}{|c|c|c|c|c|c|c|}
\hline \multirow[t]{3}{*}{ No. } & \multirow[t]{3}{*}{ Lokasi Pengukuran } & \multirow{3}{*}{$\begin{array}{c}\text { Spesifikasi } \\
\text { Teknis } \\
\left(\mathbf{C i} / \mathbf{m}^{3}\right)\end{array}$} & \multicolumn{4}{|c|}{ Hasil pengukuran $\left(\mathrm{Ci} / \mathrm{m}^{3}\right)$} \\
\hline & & & \multicolumn{2}{|c|}{ O MW } & \multicolumn{2}{|c|}{$15 \mathrm{MW}$} \\
\hline & & & Rerata & Maks & Rerata & Maks \\
\hline 1. & $\begin{array}{l}\text { Stack } \\
\text { (KLK06 CR002) }\end{array}$ & $\leq 5 \times 10^{-4}$ & $1,0 \times 10^{-4}$ & $1 \times 10^{-4}$ & $1 \times 10^{-4}$ & $1 \times 10^{-4}$ \\
\hline 2. & $\begin{array}{l}\text { Stack } \\
\text { (KLK06 CR001) }\end{array}$ & $\leq 5 \times 10^{-4}$ & $1,0 \times 10^{-7}$ & $1 \times 10^{-7}$ & $2 \times 10^{-7}$ & $2 \times 10^{-7}$ \\
\hline
\end{tabular}

Tabel 3. Hasil uji gas mulia (noble gas) pada cerobong RSG GAS pada saat operasi Teras 74 (Tahun 2014) $)^{[5]}$

\begin{tabular}{|c|c|c|c|c|c|c|}
\hline \multirow[t]{3}{*}{ No. } & \multirow[t]{3}{*}{ Lokasi Pengukuran } & \multirow{3}{*}{$\begin{array}{c}\text { Spesifikasi } \\
\text { Teknis } \\
\left(\mathbf{C i} / \mathbf{m}^{3}\right)\end{array}$} & \multicolumn{4}{|c|}{ Hasil pengukuran $\left(\mathrm{Ci} / \mathrm{m}^{3}\right)$} \\
\hline & & & \multicolumn{2}{|c|}{ 0 MW } & \multicolumn{2}{|c|}{$15 \mathrm{MW}$} \\
\hline & & & Rerata & Maks & Rerata & Maks \\
\hline 1 & $\begin{array}{l}\text { Stack } \\
\text { (KLK 06 CR 002) }\end{array}$ & $1,9 \times 10^{4}$ & $3,79 \times 10^{3}$ & $4,44 \times 10^{3}$ & $3,76 \times 10^{3}$ & $4,44 \times 10^{3}$ \\
\hline 2 & $\begin{array}{l}\text { Stack } \\
\text { (KLK } 06 \text { CR 001) }\end{array}$ & $1,9 \times 10^{4}$ & $3,79 \times 10^{0}$ & $4,44 \times 10^{0}$ & $4,35 \times 10^{0}$ & $3,70 \times 10^{1}$ \\
\hline
\end{tabular}


Tabel 4. Hasil uji gas mulia (noble gas) pada cerobong RSG GAS pada saat operasi Teras 89 (Tahun 2015) ${ }^{[5]}$

\begin{tabular}{|c|c|c|c|c|c|c|}
\hline \multirow[t]{3}{*}{ No. } & \multirow[t]{3}{*}{ Lokasi Pengukuran } & \multirow{3}{*}{$\begin{array}{c}\text { Spesifikasi } \\
\text { Teknis } \\
\left(\mathrm{Ci} / \mathbf{m}^{3}\right)\end{array}$} & \multicolumn{4}{|c|}{ Hasil pengukuran $\left(\mathrm{Ci} / \mathrm{m}^{3}\right)$} \\
\hline & & & \multicolumn{2}{|c|}{$\mathbf{0} \mathbf{M W}$} & \multicolumn{2}{|c|}{$15 \mathrm{MW}$} \\
\hline & & & Rerata & Maks & Rerata & Maks \\
\hline 1 & $\begin{array}{l}\text { Stack } \\
\text { (KLK } 06 \text { CR 002) }\end{array}$ & $1,85 \times 10^{4}$ & $4,11 \times 10^{3}$ & $6,14 \times 10^{3}$ & $4,89 \times 10^{3}$ & $7,23 \times 10^{3}$ \\
\hline 2 & $\begin{array}{l}\text { Stack } \\
\text { (KLK } 06 \text { CR 001) }\end{array}$ & $1,85 \times 10^{4}$ & $8,17 \times 10^{\circ}$ & $2,48 \times 10^{1}$ & $2,18 \times 10^{1}$ & $4,42 \times 10^{1}$ \\
\hline
\end{tabular}

Berdasarkan penelitian yang telah dilakukan oleh Yulius Sumargo, Unggul Hartoyo dkk., yang dilakukan pada Tahun 2008 ${ }^{[11]}$, dilaporkan bahwa kandungan radionuklida yang pernah terdeteksi pada cerobong gas buang RSG GAS adalah unsur-unsur : I-131, Ba-131,
$\mathrm{Pb}-214, \mathrm{I}-133, \mathrm{Bi}-214$, Cs-137, Co-60 dan K40, seperti ditunjukkan pada Tabel $5^{[11]}$. Pemantauan gas buang/emisi dari reaktor riset atau PLTN pada umumnya difokuskan pada radionuklida yang memiliki waktu paruh lebih dari 8 hari $^{[13]}$.

Tabel 5. Hasil uji sampel gas buang cerobong RSG GAS yg tertangkap oleh filter yang dilakukan pada Tahun $2008^{[11]}$

\begin{tabular}{cccc}
\hline No. & Nuklida & Energy (keV) & Cacah (cps) \\
1 & $\mathrm{I}-131$ & 80,18 & 1841 \\
2 & $\mathrm{Ba}-131$ & 239,63 & 815 \\
3 & $\mathrm{~Pb}-214$ & 295,22 & 931 \\
4 & $\mathrm{I}-132$ & 364,48 & 5676 \\
5 & $\mathrm{I}-133$ & 510,40 & 199 \\
6 & $\mathrm{Bi}-214$ & 609,32 & 654 \\
7 & $\mathrm{Cs}-137$ & 661,62 & 181 \\
8 & $\mathrm{Co}-60$ & 1173 & 106 \\
9 & $\mathrm{~K}-40$ & 1460,75 & 1995 \\
\hline
\end{tabular}

Batas paparan maksimum dari gas buang cerobong RSG GAS berdasarkan LAK RSG-GAS Rev. 10.1, Tahun 2011 adalah $1 \mathrm{x}$ $10^{15} \mathrm{~Bq} / \mathrm{m}^{3}$. Analisis LOR, selama 10 tahun operasi nilai batas tersebut tidak pernah terlam- paui. Hasil analisis seluruh Laporan Operasi RSG GAS dari tahun 2005 sampai dengan tahun 2015 ditunjukkan pada Gambar 2 dan Gambar 3. 


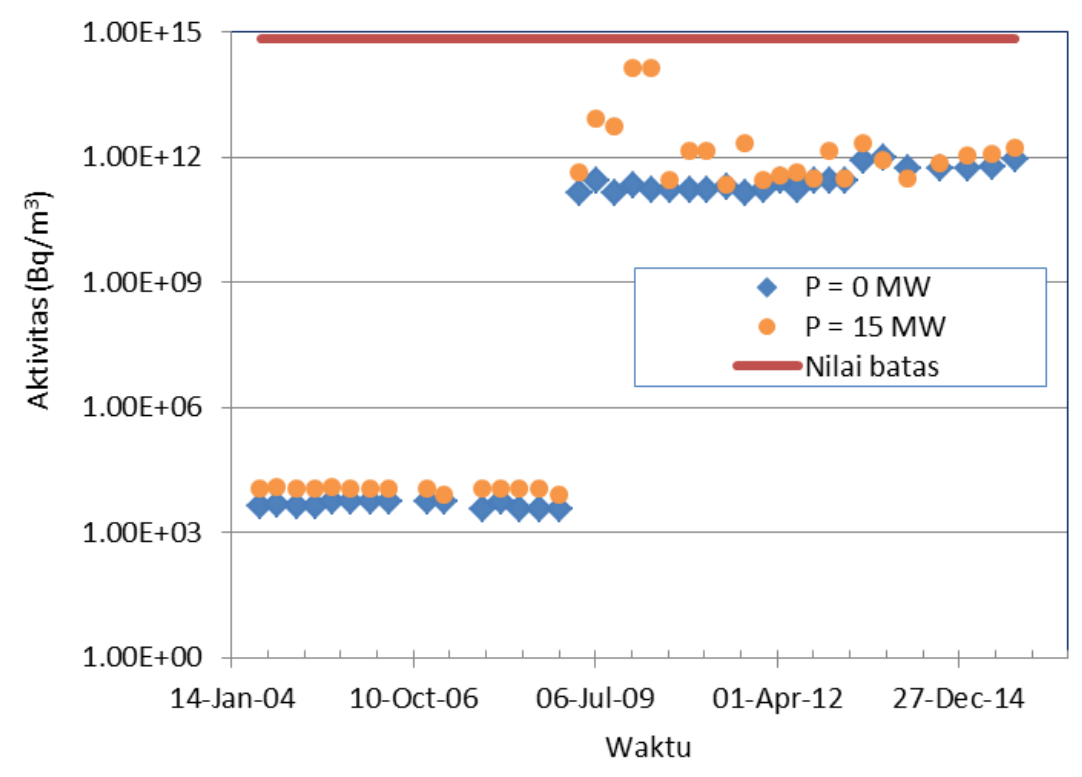

Gambar 2. Aktivasi gas mulia di stack KLK06 CR001

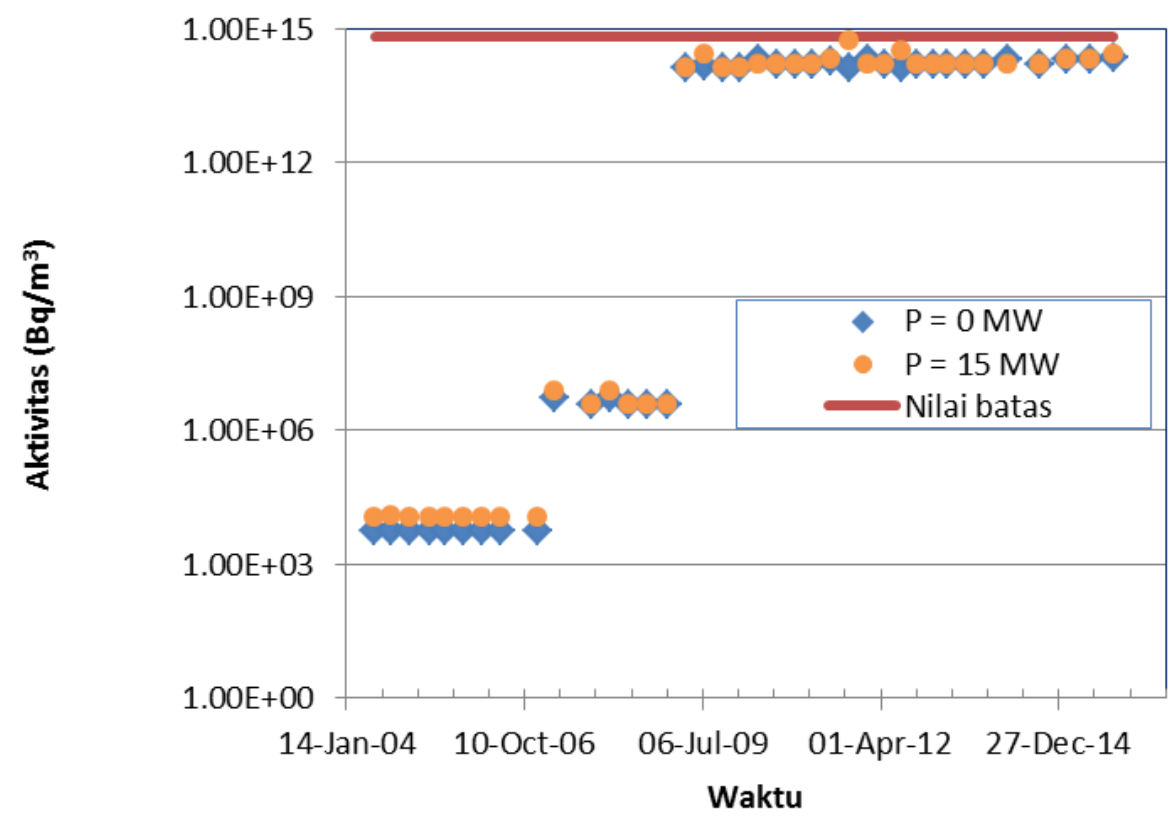

Gambar 3. Aktivasi gas mulia di stack KLK06 CR002 
Ada 2 kondisi operasi yang disampling, yaitu kondisi operasi $0 \mathrm{MW}$ (pada saat reaktor shutdown) dan kondisi operasi $15 \mathrm{MW}$. Ratarata RSG GAS dioperasikan pada daya $15 \mathrm{MW}$. Pada saat reactor shutdown nilai paparan radiuonuklida dari cerobong jauh lebih kecil dibandingkan pada saat operasi. Perbedaan itu diperkirakan rata-rata sebesar $5 \times 10^{3} \mathrm{~Bq} / \mathrm{m}^{3}$. Pada saat operasi $15 \mathrm{MW}$, kenaikan paparan diperkirakan berasal dari perubahan sistem reaktor, dari sistem yang statis menjadi sistem yang dinamis. Pada saat reaktor shutdown sistem pendingin primer tidak beroperasi sehingga produk-produk fisi berbentuk gas tidak terbawa ke permukaan. Meskipun terjadi perbedaan pada saat shutdown dan operasi $15 \mathrm{MW}$, nilai total keduanya tidak melewati batas ambang yang ditetapkan dalam LAK RSG-GAS.

Jika dilihat dari Gambar 2 dan 3, terjadi anomali kenaikan paparan yang cukup signifikan yaitu mulai Tahun 2009. Kenaikan paparan sangat signifikan yaitu rata-rata sebesar 7000 kali (pada daya $15 \mathrm{MW}$ ) dan 4000 kali pada daya 0 MW. Berdasarkan analisis LOR diketahui bahwa kenaikan ini diakibatkan oleh belum digantinya filter charcoal pada cerobong. Setelah filter diganti maka nilai paparan gas kembali turun sesuai Laporan Operasi Tahun 2010 dari semula $1,0 \times 10^{-4} \mathrm{Ci} / \mathrm{m}^{3}$ menjadi $2,0 \mathrm{x}$ $10^{-7} \mathrm{Ci} / \mathrm{m}^{3}$. Hasil pengukuran paparan radiasi yang berasal dari gas mulia pada cerobong RSG GAS masih dalam batas yang ditetapkan pada LAK (Laporan Analisis Keselamatan) baik pada daya $0 \mathrm{MW}$ ataupun $15 \mathrm{MW}$. Nilai pemantauan masih dibawah nilai ambang $1 \times 10^{15} \mathrm{~Bq} /$ $\mathrm{m}^{3}$, sehingga pengoperasian RSG GAS tidak mencemari lingkungan sekitarnya.

\section{KESIMPULAN}

Ada 2 kondisi operasi yang disampling dan dilaporkan dalam LOR, yaitu kondisi operasi $0 \mathrm{MW}$ (pada saat reaktor shutdown) dan kondisi operasi 15 MW. Reactor RSG- GAS dioperasikan pada daya $15 \mathrm{MW}$. Pada saat reactor shutdown nilai paparan radiuonuklida dari cerobong jauh lebih kecil dibandingkan pada saat operasi. Perbedaan itu diperkirakan rata- rata sebesar $5 \times 10^{3} \mathrm{~Bq} / \mathrm{m}^{3}$. Pada saat operasi 15 MW, kenaikan paparan diperkirakan berasal dari perubahan sistem reaktor, dari sistem yang statis menjadi sistem yang dinamis. Hasil pengukuran paparan radiasi yang berasal dari gas mulia pada cerobong RSG GAS masih dalam batas yang ditetapkan pada LAK. Berdasarkan LAK disebutkan bahwa batas paparan maksimum dari gas buang RSG GAS adalah $1 \times 10^{15} \mathrm{~Bq} / \mathrm{m}^{3}$. Hal ini didukung dengan fakta bahwa berdasarkan Laporan Operasi Reaktor (LOR), selama 10 tahun (tahun 2015-2015) operasi nilai batas ini tidak pernah terlampaui baik pada daya $0 \mathrm{MW}$ ataupun $15 \mathrm{MW}$.

\section{UCAPAN TERIMA KASIH}

Penelitian ini terselenggara atas DIPA PTKRN Tahun 2017, terima kasih yang sebesar-besarnya kepada Ka. PTKRN yang telah mendukung riset ini. Demikian juga seluruh anggota Tim di KAK Penuaan dan Tim Panitia Keselamatan Berkala (RSG GAS) yang tidak dapat disebut satu persatu.

\section{DAFTAR PUSTAKA}

1. Udiyani P.M. Perhitungan dispersi zat radioaktif reaktor RSG GAS pada kondisi operasi normal pada daya $30 \mathrm{MW}$. Prosiding PPI-PDIPTN 2016, ISSN 0216-3128

2. Udiyani P.M., Suparlina L., Wijaya R. Analisis neutronik dan keselamatan radiologi reaktor RSG GAS pada teras uranium silisida 300 gram. Prosiding PPI-PDIPTN 2017, ISSN 0216-3128

3. SUBIHARTO. Pemantauan kandungan H-3 dan C-14 teras 70 pada air pendingin RSG GAS. Buletin Pengelolaan Reaktor Nuklir 2012; 7 (2): 1-5

4. Sukmana J., Korua J.A., Suwarto S. Analisis kuantitatif source term RSG GAS pada operasi daya $15 \mathrm{MW}$. Buletin Pengelolaan Reaktor Nuklir 2010; 7 (2): 39-50 
5. Pusat Reaktor Serba Guna (PRSG). Laporan Operasi Reaktor Serba Guna GA Siwabessy, Tahun 2005-2015 (Teras 50-89), 2015

6. International Atomic Energy Agency. Safety of Research Reactors, Safety Requirements No. NS-R-4, Vienna 2010

7. Wijayanto A., Kwin P., Purwantara. Pemilihan jalur filter udara sebelum keluar cerobong menggunakan indikator tingkat aktivitas radionuklida di $\mathrm{KH}-$ IPSB3. Prosiding seminar penelitian dan pengelolaan perangkat nuklir 2012, Pusat Teknologi Akselerator dan Perangkat Bahan Nuklir (PTAPB), Yogyakarta

8. Luhur N., Anthony S., Syafrul, Sukino. Kajian gangguan dan pengaturan pompa hisap system pemantau gas mulia RSG GAS. Prosiding seminar Penelitian dan Pengelolaan Perangkat Nuklir 2011, Pusat Teknologi Akselerator dan Perangkat Bahan Nuklir (PTAPB), Yogyakarta

9. Yuwono I., Pujadi E. Penyebaran radioaktivitas ALPHA dan BETA ke lingkungan dari pengujian elemen bakar bekas di IRM. Prosiding Pertemuan dan Presentasi Ilmiah 1995, PPNY-BATAN, Yogyakarta, ISSN 0216-3128

10. Christoudias T., Yiannis P., Lelieveld J. Atmospheric dispersion of radioactivity from nuclear power plants: Global assessment and case study for the Eastern Mediterranean and Midle East, Energies Journal 2014; 7: 8338-8354, DOI: 10.3390

11. Sumarno Y., Hartoyo U., Muslimu F.A. Analisis konsentrasi I-131 lepasan udara cerobong di Reaktor Serbaguna GA Siwabessy. Prosiding Seminar Nasional SDM Teknologi Nuklir 2012, Yogyakarta

12. Fortini M., Clarysson S., Ferreira A., Pereira C. Evaluation of height chimney effect in a research reactor core. In: International Nuclear Atlantic Conference (INAC) 2017, Santos, SP, Brazil
13. Christoudias T., Yiannis P., Lelieveld J. Global risk from the atmospheric dispersion of radionuclides by nuclear power plant accidents in the coming decades. Atmospheric Chemistry Physics 2014; 14: 4607-4616

14. Suharyono G, Sutarman, June M. Studi Pemantauan Emisi Udara Radioaktif Dari Cerobong PLTN dan Kendali Kualitasnya. Prosiding SENPEN II 2015, Pusat Pengkajian Energi Nuklir 